\title{
PIAGET Y FREUD: ACERCA DE LA MEMORIA INFANTIL
}

\author{
Manuel Arboccó de los Heros ${ }^{1}$ \\ Universidad Inca Garcilaso de la Vega, Lima, Perú \\ (RECIBIDO EL 5/10/2009, ACEPTADO EL 2/12/ 2009)
}

\begin{abstract}
RESUMEN
En el siguiente trabajo se reflexiona a partir de la búsqueda de algún paralelismo entre los estudios de Jean Piaget y la obra de Sigmund Freud en torno al tema de uno de los procesos mentales más importantes: la memoria; y más específicamente la memoria infantil.
\end{abstract}

Palabras clave: Inconsciente, fantasías, simbolismo, cognición, histeria, represión, asimilación, esquemas mentales, sensorio-motor, operaciones mentales, inteligencia.

\section{ABSTRACT \\ PIAGET AND FREUD: ABOUT CHILDHOOD MEMORY}

In the following work, it is meditated starting from the search of some parallelism between Jean Piaget's studies and Sigmund Freud's work, around the topic of one of the most important mental processes: the memory; and more specifically the infantile memory.

Keywords: Unconscious, fantasy, symbolism, cognition, hysteria, repression, assimilation, mindsets, sensory motor, mental operations, intelligence.

\section{INTRODUCCIÓN}

En las siguientes páginas se indicarán aquellos puntos de concordancia, por mínimos que sean, así como aquellos campos donde las explicaciones son disímiles u opuestas. Existe algo de riesgo en tratar de unir a Piaget con Freud pero la esperanza de algún encuentro es estimulante. Hace mucho tiempo ya la lectura de un ensayo de Edward S. Casey estimuló el artículo que hoy presento.

Veamos. Si bien Jean Piaget pasó por un corto periodo en psicoanálisis, fue rápidamente opuesto a los planteamientos de Freud y llega a indicar que sus "concepciones teóricas requerían de un cambio general". Inicialmente la memoria fue un tema que a Freud le interesó mucho, pero luego pasa a ser la "fantasía en el pensamiento" el tema de mayor atención; por su parte Piaget, si bien en un inicio no le dedica mucho espacio en sus escritos, es al final de su obra cuando publica Memoria e inteligencia.

Ya con respecto a la memoria infantil, puede verse que a Freud lo que más le preocupa es a donde van a parar los recuerdos infantiles tempranos, y sus repercusiones en la

1 Docente de la Universidad Inca Garcilaso de la Vega. E-mail: manoloarb@uigv.edu.pe 
vida adulta, además (y esto es quizá uno de los tantos aportes al entendimiento de la personalidad en su totalidad) presta atención a la imperfección de estos recuerdos. Esto lo menciona en su ensayo Psicopatología de la vida cotidiana cuando señala que muchos supuestos recuerdos infantiles son erróneos, son mezclas de recuerdos con fantasías y que su finalidad es encubrir inconscientemente lo que sucedió durante esos años, los llamó recuerdos encubridores. Es más, llega a señalar que en vez de decir que tenemos recuerdos de nuestra infancia probablemente lo único que realmente podemos decir es que tenemos solo recuerdos relacionados a nuestra infancia. Así Freud hace hincapié en el carácter autoengañador y autodirectivo de nuestra mente.

Por su parte Jean Piaget pareciera preferir tomar la memoria infantil y no la adulta por llegar a considerar que en el adulto las funciones mentales se han vuelto demasiado complejas para poder ser captadas por el propio sujeto y por eso se vuelve a donde considera tener mayor oportunidad de comprender la memoria, qué mejor que con los niños.

Cierto es que Piaget y Freud logran hacer sus atisbos más originales y reveladores privilegiando la infancia como un campo de investigación. Freud tomó (luego lo hace igualmente Piaget) la vida infantil -sobre todo la vida sexual (entiéndase sexual en su mayor dimensión)- y la elaboró como muchos otros teóricos de su época no lo hicieron, quizá por subestimación, por prejuicios, por temor o desinterés.

Un punto en común se encuentra en la preocupación freudiana no sólo por lo afectivo, como pudiera pensarse y en el caso de Piaget, no sólo por lo cognitivo. Ambos buscarían -si bien no trabajarían ambos campos por igual- el considerar tanto lo afectivo como lo intelectual. Además Freud si bien trataba básicamente a pacientes adultos no descuida para nada la importancia de los primeros recuerdos en la infancia, al contrario, la importancia de la infancia para la formación de la estructura de la personalidad es básica dentro del psicoanálisis.

Por su parte Piaget llega a pensar que con su teoría sobre la memoria infantil podemos llegar a obtener alguna percepción de la naturaleza de la memoria adulta.

Estas son algunas de las convergencias entre estos dos grandes estudiosos de la mente humana.

\section{FREUD Y PIAGET}

\section{Los símbolos mnémicos}

Un caso famoso de Freud llamado "El hombre de los lobos" servirá para entender el carácter que el psicoanálisis le da a la memoria. Se trata de un joven paciente que visita a Freud a causa de una fobia a los lobos. En la primera parte de su psicoanálisis, el paciente mencionó un sueño por demás particular y que daría a Freud la idea para el seudónimo a su paciente. Este sueño, producido a los cuatro años de edad, consistía en la presencia inmóvil de varios lobos junto a un árbol alrededor del soñador a quien miraban fijamente. Freud supuso que su paciente había presenciado la llamada escena primaria (visión filial de la cópula paterna) a la edad de un año y medio y que como en todo sueño lleno de simbolismos, la inmovilidad de los lobos era una cubierta para los violentos movimientos 
de sus padres en la relación sexual y la mirada fija de los lobos era en realidad su propia mirada sobre sus padres en el acto. Obviamente como muchos pacientes, el ahora llamado "hombre de los lobos" no recordaba esta experiencia y Freud supuso que escenas de este tipo (traumáticas) no debían ser fácilmente recordadas y que sólo podían ser reconstruidas en el psicoanálisis.

De este caso en particular se desprende claramente las tres principales formas de recuerdo que operan en la situación analítica: el recuerdo (del sueño de los lobos), la repetición (de la escena primaria por este sueño) y la reconstrucción (de la original escena).

Según Freud, el paciente con este sueño "recordaba" así lo sucedido, y la siguiente fobia a los lobos que nació inmediatamente después del sueño, trata a los lobos como "símbolos mnémicos" o símbolos de la memoria.

De esta forma el sueño repetía la escena primaria o primigenia y la fobia a los lobos repetía o mantenía el sueño, o mantenía el recuerdo pero a nivel inconsciente. Pero desde el principio de sus estudios Freud descubre que "un recuerdo es más que la copia de un hecho pasado", tiene su propia eficacia causal, es decir puede también ser "causa de...". En su famoso ensayo Estudios sobre la histeria, Freud afirma que aquellas impresiones del periodo presexual que no produjeron efecto en el niño en su momento, alcanzaban un poder traumático luego, como recuerdos. De aquí es valioso lo que se desprende: ciertas impresiones no ejercen un efecto considerable (esto es, no son traumáticas) hasta un momento posterior pero este efecto es ejercido por los recuerdos que son "pálidas copias" de sus causas. Si bien las impresiones pueden ser patógenas (que pueden originar patología) es el recuerdo el que actúa específicamente como causa del inicio de la histeria, para el caso del "hombre de los lobos".

En conclusión, un recuerdo sería el efecto del hecho real, pero luego este recuerdo se convierte en sí mismo en un hecho y es así como tiene tanta fuerza para la psique del que recuerda.

Aparece aquí otro punto importante, la llamada acción diferida, que sería aquella posterior situación que por su parecido inconsciente a la primera (por algún nexo simbólicamente similar) desencadena en la persona una situación posiblemente traumática cuando lo que ha sucedido es que a través de esa situación aparentemente inofensiva se recordó por diferido el primer suceso traumático.

Se puede decir que en el pasado se da una mezcla de presencia y ausencia. Lo que está presente es la imagen de memoria pero lo ausente es la experiencia original que si bien ya no está, queda inventada por y en la imagen. La experiencia del pasado vuelve a la mente a través de estas imágenes de memoria. Es entendible ahora el escepticismo de Freud luego de acercarnos ligeramente a su enorme teoría. Luego de éste no podemos dar por de contado cuán exactamente está siendo representada la experiencia por la imagen -que puede deformarla con algún propósito, sobre todo inconsciente. Además queda la duda si lo que tomamos como la experiencia pasada fue una experiencia y no un producto iluso de nuestra mente. Puede suceder.

Para finalizar con este caso, pareciera que la llamada acción diferida se produjo con el sueño a los cuatro años, sueño que le produjo una fobia. Pero puede surgir la pregunta 
¿por qué soñó eso a los cuatro años?, la posible respuesta dada por el propio Freud es que a la edad estimada de un año y medio el entonces niño recibió una impresión que no podía tramitar, no podía entender bien, pero que si lo marca y vive en él y cuando la impresión revive a la edad de cuatro años por un "avance del desarrollo intelectual" (y yo le añadiría del desarrollo psicosexual) es cuando viene el sueño simbólico y sólo luego del proceso psicoanalítico es cuando el paciente asimila y logra captar con sus procesos mentales ahora desarrollados todo el sentido del mismo (del sueño y de la fobia).

\section{La imagen de memoria}

Una primera idea fuerte es que lo que la memoria retiene es básicamente lo que el sujeto ha entendido. Piaget en su libro Memoria e Inteligencia expone veinte experimentos dónde muestra que unos niveles de desempeño al recordar un objeto o acontecimiento particular están casi invariablemente relacionados con los niveles de entendimiento del mismo objeto o acontecimiento.

Esto no significa que sólo se recuerde lo que se comprende, ya que a veces pueden recordarse detalles pequeños no comprendidos, sin sentido, pero sí significa que la parte principal y más importante de lo que recordamos se refleja en función de lo captado por nuestro entendimiento.

Piaget nos habla de esquemas que guían la inteligencia. Los esquemas de piagetianos son procedimientos para asimilar experiencia y comprenderlas en su generalidad. Son las bases para la acomodación de nuevas experiencias. Distingue tres tipos de memoria:

- Reconocimiento: va de la mano con la percepción, asimila el objeto a esquemas sensorio-motores.

- Reconstrucción: proceso por el cual se reconstruye deliberadamente una acción particular en ausencia del modelo o la experiencia original.

- $\quad$ Recuerdo (evocación): se logra mediante imágenes de memoria o palabras que sirven como representaciones del contenido evocado.

Piaget indica que una imagen de memoria nunca es una reproducción estricta de semejante escena y su significado no es la escena originalmente comprendida sino la escena solicitando los esquemas por los cuáles fue asimilada y así comprendida. Para la conservación de recuerdos depende la conservación de esquemas y los esquemas pertenecen a la inteligencia. Pero no hay que confundir, la memoria depende de la inteligencia más de lo que la inteligencia depende de ella. La tesis principal de Piaget es que "el desarrollo de la memoria con la edad es la historia de unas organizaciones graduales muy dependientes de las actividades estructurales de la inteligencia”. La memoria es un constante proceso de reestructuración.

Piaget presenta experimentos dónde se comparan niveles de memoria en niños de distinta edad cronológica, a través de ejercicios en los que los niños observan gráficos o cuadros. Se menciona que los avances de la memoria van atados a los avances del esquema operacional al que se ha asimilado el modelo de la serie. Piaget habla pues de esquemas que evolucionan. 
Las áreas evaluadas en los experimentos son: esquemas de seriación; de correspondencia numérica; de conservación espacial; seriaciones simultáneas; cada una relacionada de acuerdo a las etapas evolutivas de Piaget: sensorio-motriz, preoperacional, de las operaciones concretas y de las operaciones formales. En algunos casos la clave de un buen resultado era el buen entendimiento de una figura ya que en casos donde la figura a recordar era algo bizarra o extraña antes de recordarla había que entenderla.

Así, se establece que la memoria es activa y selectiva y no solamente una caja de almacenamiento de datos. Según Piaget la memoria no es cosa de codificación instantánea, pues el código mismo evoluciona en el curso de la retención y evoluciona de acuerdo con los esquemas subyacentes de los que depende para su inteligibilidad.

Una diferencia entre Freud y Piaget es que para el segundo, los cambios de memoria son cualitativos y afectan tanto su contenido como sus mecanismos. Según Freud todo recuerdo que supuestamente proceda de la infancia es potencialmente un recuerdo encubridor. Freud subraya la forma en que reorganizamos el pasado según conviene a nuestras necesidades y deseos del presente. Lo reorganizamos a través de falsos recuerdos, amnesias, negaciones, olvidos, sueños y algunos de los llamados mecanismos de defensa del yo.

Retomando una vez más, el caso del hombre de los lobos, se puede continuar diciendo que lo que entró en actividad la noche del sueño a partir de las "huellas de memoria inconsciente" fue la imagen de la copulación de sus padres, pero en forma diferida para reducir la tensión, por eso el simbólico sueño de los lobos fue el único modo aceptable para el yo del niño de recordar el hecho traumático experimentado tiempo atrás. Si, en este caso, se trata pues de experiencias infantiles que en su momento no fueron comprendidas pero que después sí, y se les interpretó.

Según Piaget la memoria evoluciona (no es inmutable) y lo hace sistemáticamente de acuerdo a la evolución de la inteligencia. La acción diferida por la memoria ocurre porque la memoria misma está en desarrollo y posee un componente cognitivo -el entendimientoque va unido a la inteligencia. El individuo reorganiza continuamente el pasado en sus esquemas.

\section{VIVIR EL RECUERDO}

"Yo he hecho eso", dice mi memoria. "Yo no puedo haber hecho eso" -dice mi orgullo- y permanece inflexible. Al final, la memoria cede.

Friedrich Nietzsche

La sentencia de Nietzsche nos recuerda el papel que las necesidades tienen en la memoria del individuo. Si la participación es consciente, es decir abiertamente se niega, modifica o disfraza un recuerdo esto no tendría por sí mismo más valor que el que puede tener una mentira o una impostación, pero si se trata de situaciones que inconscientemente influyen en la contaminación del recuerdo de una escena original, entonces, como se vio líneas atrás, la desconfianza de Freud a los recuerdos debe de tenerse presente cuando del tema se trate. 
Se ha dicho que el recuerdo opera como un hecho contemporáneo, es en el presente, en el hoy cuando volvemos a vivir la experiencia recordada, o la experiencia tal y como creemos que ocurrió. No es pues el pasado el que nos incomoda cuando de recuerdos infelices se trata, es en el presente cuando seguimos "viviendo el recuerdo" (o el supuesto recuerdo).

Aprendí hace algunos años a desconfiar de mi propia memoria. Esto por el contacto con algunas investigaciones sobre la memoria en la que se ha establecido aquello que Freud indicara casi un siglo antes. No siempre las cosas sucedieron tal y como nosotros lo creemos. La memoria tiene anomalías que pueden deberse tanto a factores netamente psicológicos como a componentes bioquímicos cerebrales y ni hablar del deterioro orgánico que ocurre normalmente con el pasar de los años. Somos más imperfectos de lo que creemos y la memoria también esconde lo suyo.

Se ve que Freud habla de un "avance en el desarrollo intelectual" sin entrar en más detalles del porqué el llamado "hombre de los lobos" tuvo ese sueño a los cuatro años en especial. Por su parte, Piaget habla de "esquemas afectivos" cuando quiere referirse a algo propio del aspecto subjetivo del individuo, tema el que, no es su "fuerte".

Sin temor a equivocarme, creo que de todas maneras, y más allá de sus diferencias o no, cuando de investigar o estudiar sobre la memoria, tanto Freud como Piaget deben ser consultados necesariamente.

Quisiera terminar este trabajo mencionando brevemente, algunas opiniones tomadas directamente de Jean Piaget como de Sigmund Freud. Reflexiones tomadas de sus trabajos Seis estudios de Psicología, de Piaget; y de los ensayos de Freud: Psicopatología de la vida cotidiana y El falso reconocimiento durante el psicoanálisis.

\section{Seis estudios de psicología, el desarrollo mental del niño, equilibración y estructuras}

Según Piaget el desarrollo psíquico que se inicia con el nacimiento y finaliza en la edad adulta es comparable al crecimiento orgánico y al igual que este consiste en una marcha hacia el equilibrio. Entonces el desarrollo es un progresivo equilibrarse, un continuo paso de un estado menos equilibrado a un estado superior de equilibrio. Además existen funciones constantes comunes a todas las edades pero lo que varía de un nivel mental a otro son los "intereses". Existen estructuras progresivas o formas sucesivas de equilibrio que van apareciendo según el grado de desarrollo intelectual, para el caso tratado.

Cada una de las etapas evolutivas establecidas por Piaget se caracteriza por la aparición de estructuras originales, cuya construcción la distingue de las etapas anteriores. De esto se desprende que en el adulto cada una de estas etapas pasadas corresponde a un nivel más o menos elemental o elevado de la jerarquía de las conductas. Cada etapa constituye, mediante las estructuras que la definen, una forma particular de equilibrio, y la evolución mental se efectúa en el sentido de una equilibración cada vez mejor. A cada momento la acción conlleva un desequilibrio por las transformaciones que surgen en el mundo (exterior o interior) y cada nueva conducta consiste no sólo en restablecer el equilibrio, sino también en tender hacia un equilibrio más estable que el del estado anterior a esta perturbación. 
Conviene recordar lo que decía otro estudioso como Claparede: "una necesidad es siempre la manifestación de un desequilibrio".

Para Piaget, toda necesidad tiende a:

- Incorporar las cosas y las personas a la actividad propia del sujeto, y por tanto a "asimilar" el mundo exterior a las estructuras ya construidas.

- Reajustar estas en función de las transformaciones experimentadas y por tanto a "acomodarlas" a los objetos externos.

Se puede denominar adaptación al equilibrio de estas asimilaciones y acomodaciones.

Desde este punto de vista, toda la vida mental, así como también la propia vida orgánica, tiende a asimilar progresivamente el medio ambiente y lleva esta incorporación mediante estructuras.

\section{Freud y la psicopatología de la vida cotidiana: recuerdos infantiles y recuerdos encubridores}

En este ensayo Freud indica que los recuerdos infantiles indiferentes deben su existencia a un proceso de desplazamiento y constituyen en la reproducción un sustitutivo de otras impresiones verdaderamente importantes cuya reproducción se halla estorbada por una resistencia que será levantada por medio del psicoanálisis. Por eso Freud los llamó "encubridores".

Hace una distinción importante entre el olvido de nombres y los recuerdos encubridores. Mientras que el olvido de nombres no constituye más que una perturbación momentánea -pues el nombre que se acaba de olvidar ha sido reproducido en otras oportunidades con exactitud y puede volver a serlo-; en cambio los recuerdos encubridores son algo que poseemos durante largo tiempo sin que sufran perturbación alguna, dado que los recuerdos infantiles indiferentes parecen poder acompañarnos, sin perderse, a través de un amplio periodo de nuestra vida.

Freud se pregunta: “¿hasta qué estadio de la niñez alcanzan los recuerdos?” Mientras que en algunos el primer recuerdo infantil corresponde a la edad de seis meses, otros no recuerdan nada de su vida anterior a los seis y a veces a los ocho años cumplidos. Señala que se mira con indiferencia el hecho de esta amnesia infantil.

Sin embargo, en la actualidad se ha comprobado que el desarrollo de la memoria es un proceso gradual: el registro, la retención y el recuerdo son menos eficientes antes del desarrollo del lenguaje. Nadie sabe a ciencia cierta con cuanta fidelidad recuerdan los niños de tres o cuatro años acontecimientos sucedidos en periodos anteriores, cuya memoria estaría condenada a desaparecer.

De aquí que no deba sorprender a nadie que antes del desarrollo completo del lenguaje, los recuerdos no puedan ser retenidos adecuadamente.

Freud es tajante cuando afirma "si se someten a un examen analítico los recuerdos que de su infancia ha conservado una persona, puede sentarse fácilmente la conclusión de que 
no existe ninguna garantía de la exactitud de los mismos”. Algunas de las imágenes del recuerdo aparecerán falseadas, incompletas o desplazadas temporal y espacialmente.

En su ensayo El falso reconocimiento durante el psicoanálisis mantiene su idea sobre la incredulidad para con la memoria: "... sabemos que este sentimiento de confianza en la fidelidad de la memoria carece de todo valor objetivo...".

\section{CONCLUSIONES}

A Freud le preocupan los recuerdos infantiles tempranos, la imperfección de éstos y su repercusión en la formación de la psique adulta.

Hace hincapié en el carácter autoengañador y autodirectivo de nuestra mente.

Mientras que Freud se dedicó a la psicoterapia y trabajó con pacientes adultos buscando en sus recuerdos las causas de sus síntomas, Piaget -quién no fue psicólogo y menos terapeuta, aunque no por eso su trabajo deja de tener enorme importancia en Psicologíallega a pensar que con su teoría sobre la memoria infantil podemos llegar a obtener alguna percepción de la naturaleza de la memoria adulta.

Una impresión puede ser neurotizante, sin embargo, el recuerdo de esa imagen lo es también, o a veces más. Un recuerdo sería el efecto del hecho real, pero luego este recuerdo se convierte en sí mismo en un hecho particular.

Podemos recordar situaciones que no han ocurrido o que no hemos entendido del todo.

La memoria depende de la inteligencia más de lo que la inteligencia depende de ella. Los avances de la memoria van atados a los avances del esquema operacional al que se ha avanzado.

\section{REFERENCIAS BIBLIOGRÁFICAS}

1. Casey, E. (1993). Piaget y Freud sobre la memoria infantil. En Silverman, H. (comp) Piaget, la filosofía y las ciencias humanas.

2. Flavell, J. H. (1995). La psicología evolutiva de Jean Piaget. México. D.F.: Paidós.

3. Freud, S. (1899). Sobre los recuerdos encubridores: En Obras completas de Sigmund Freud. Volumen III; Buenos Aires: Amorrortu Editores

4. Freud, S. (1901). Psicopatología de la vida cotidiana; Buenos Aires: Amorrortu Editores.

5. Freud, S. (1905). El chiste y su relación con lo inconsciente. En Obras completas de Sigmund Freud. Volumen VIII; Buenos Aires: Amorrortu Editores.

6. Freud, S. (1918). Historia de una neurosis infantil: caso de "El hombre de los lobos". En Volumen XVII - "De la historia de una neurosis infantil" (Caso del "Hombre de los lobos"), y otras obras (1917-1919); Buenos Aires: Amorrortu Editores. 
7. Freud, S. (1920). Más allá del principio del placer. En Obras completas de Sigmund Freud. Volumen XVIII - Más allá del principio de placer, Psicología de la masas y análisis del yo, y otras obras (1920-1922); Buenos Aires: Amorrortu Editores.

8. Nietzsche, F. (1884). Así habló Zaratustra. Madrid: Alianza Editorial.

9. Piaget, J. (1964). Seis estudios de Psicología. Barcelona: Seix-Barral.

10. Piaget, J. (1972). Memoria e inteligencia. Argentina: Edit. El Ateneo.

11. Piaget, J. (1936). El nacimiento de la inteligencia en el niño. Madrid: Aguilar.

12. Piaget, J. García Rolando (1987). Lógica y epistemología genética. Hacia una lógica de las significaciones. España: Edit. Gedisa. 